\title{
Contributions of two UDP-glucose dehydrogenases to viability and polymyxin $B$ resistance of Burkholderia cenocepacia
}

\author{
Slade A. Loutet, ${ }^{1}$ S. Josefin Bartholdson,,3 John R. W. Govan, ${ }^{2}$ \\ Dominic J. Campopiano ${ }^{3}$ and Miguel A. Valvano ${ }^{1,4}$
}

Correspondence

Miguel A. Valvano

mvalvano@uwo.ca

Received 16 January 2009

Revised 7 March 2009

Accepted 16 March 2009

\author{
${ }^{1}$ Department of Microbiology and Immunology, Infectious Diseases Research Group, Siebens- \\ Drake Research Institute, University of Western Ontario, London, Ontario N6A 5C1, Canada \\ ${ }^{2}$ Centre for Infectious Diseases, University of Edinburgh Medical School, Edinburgh EH16 4SB, UK \\ ${ }^{3}$ School of Chemistry, University of Edinburgh, Edinburgh EH9 3JJ, UK \\ ${ }^{4}$ Department of Medicine, Infectious Diseases Research Group, Siebens-Drake Research Institute, \\ University of Western Ontario, London, Ontario N6A 5C1, Canada
}

\begin{abstract}
Burkholderia cenocepacia is highly resistant to antimicrobial peptides and we hypothesized that the conversion of UDP-glucose to UDP-glucuronic acid, a reaction catalysed by the enzyme UDPglucose dehydrogenase (Ugd) would be important for this resistance. The genome of $B$. cenocepacia contains three predicted ugd genes: ugd $d_{B C A L 2946}, u g d_{B C A M 0855}$ and $u g d_{B C A M 2034}$, all of which were individually inactivated. Only inactivation of $u g d_{B C A L 2946}$ resulted in increased sensitivity to polymyxin $B$ and this sensitivity could be overcome when either $u g d_{B C A L 2946}$ or $u g d_{B C A M 0855}$ but not $u g d_{B C A M 2034}$ was expressed from plasmids. The growth of a conditional $u g d_{B C A L 2946}$ mutant, created in the $\triangle u g d_{B C A M 0855}$ background, was significantly impaired under non-permissive conditions. Growth could be rescued by either $u g d_{B C A L 2946}$ or $u g d_{B C A M O 855}$ expressed in trans, but not by $u g d_{B C A M 2034}$. Biochemical analysis of the purified, recombinant forms of $\mathrm{Ugd}_{\mathrm{BCAL2946}}$ and $\mathrm{Ugd}_{\mathrm{BCAM0855}}$ revealed that they are soluble homodimers with similar in vitro Ugd activity and comparable kinetic constants for their substrates UDP-glucose and NAD ${ }^{+}$. Purified Ugd $\mathrm{BCAM}_{2034}$ showed no in vitro Ugd activity. Real-time PCR analysis showed that the expression of $u g d_{B C A L 2946}$ was 5.4- and 135-fold greater than that of $u g d_{B C A M O 855}$ and $u g d_{B C A M 2034}$, respectively. Together, these data indicate that the combined activity of $\mathrm{Ugd}_{\mathrm{BCAL2946}}$ and $\mathrm{Ugd}_{\mathrm{BCAM0855}}$ is essential for the survival of $B$. cenocepacia but only the most highly expressed ugd gene, ugd $d_{B C A L 2946,}$ is required for polymyxin B resistance.
\end{abstract}

\section{INTRODUCTION}

Burkholderia cenocepacia belongs to the Burkholderia cepacia complex (Bcc), a group of ten phenotypically similar environmental Gram-negative bacteria (Balandreau et al., 2001), which are also opportunistic human pathogens causing chronic, sometimes fatal, pulmonary infections in cystic fibrosis (CF) patients (Isles et al., 1984; Mahenthiralingam et al., 2005). Treatment of these infections is difficult as Bcc bacteria are inherently resistant to most clinically relevant antimicrobial agents (Aaron et al., 2000; Burns et al., 1996; Gold et al., 1983), including

Abbreviations: APs, antimicrobial peptides; Ara4N, 4-amino-4-deoxy-Larabinose; CF, cystic fibrosis; DDM, dodecylmaltoside; pmB, polymyxin B; Ugd, UDP-glucose dehydrogenase.

Supplementary methods and tables of strains and primers are available with the online version of this paper. antimicrobial peptides (APs) (Loutet et al., 2006; Turner et al., 1998).

APs are short, amphipathic, positively charged peptides produced by organisms from bacteria to mammals (Brogden, 2005). They are part of the innate immune response (Ganz, 2003; Zanetti, 2004) and have been shown to kill bacteria through the disruption of the inner membrane (Brogden, 2005) and also through inhibition of intracellular processes (Patrzykat et al., 2002). APs have been proposed as agents for treatment of infections by other CF lung pathogens, such as Pseudomonas aeruginosa (Zhang et al., 2005). Unfortunately, due to the extraordinary resistance of $B$. cenocepacia to the killing effects of APs, they are unlikely to be useful agents for treatment of lung infections by $B$. cenocepacia. Understanding the determinants of AP resistance in $B$. cenocepacia is important because they could provide targets for the 
development of novel antimicrobial agents that could be co-administered with APs. For example, in B. cenocepacia L-glycero-D-manno-heptose sugars of the lipopolysaccharide (LPS) core oligosaccharide are required for AP resistance and in vivo survival (Loutet et al., 2006) and small molecule inhibitors of the synthesis of these sugars have been identified (De Leon et al., 2006).

A widely recognized mechanism of AP resistance in Gramnegative bacteria is the decoration of lipid A phosphate residues with the positively charged sugar 4-amino-4-deoxyL-arabinose (Ara4N), which requires the synthesis of a UDPAra4N precursor (Ernst et al., 1999; Helander et al., 1994; Nummila et al., 1995; Vaara et al., 1981). Ara4N substitution reduces the net negative charge of the lipid A molecule and hampers the ability of APs to bind to the outer membrane (Vaara et al., 1981). In P. aeruginosa and Salmonella enterica, these substitutions are induced upon treatment with APs (Bader et al., 2005; McPhee et al., 2003) and are dispensable for growth under normal laboratory conditions. In $B$. cepacia, a species closely related to B. cenocepacia, Ara $4 \mathrm{~N}$ is constitutively incorporated into both lipid A and the LPS core oligosaccharide (Silipo et al., 2005). Preliminary evidence suggests that this is also true in $B$. cenocepacia (X. P. Ortega \& M. A. Valvano, unpublished data) and UDPAra4N synthesis was recently shown to be essential for $B$. cenocepacia viability (Ortega et al., 2007). These results highlight the importance of Ara4N in this organism and its abundance in LPS likely contributes significantly to the organism's unusually high AP resistance.

The initial step in the synthesis of UDP-Ara4N is the conversion of UDP-glucose to UDP-glucuronic acid, which is catalysed by the enzyme UDP-glucose dehydrogenase (Ugd) (Breazeale et al., 2002; Raetz \& Whitfield, 2002; Strominger et al., 1957). A recent study by Hung et al. (2007) described two Ugd-encoding genes in P. aeruginosa. Both Ugd enzymes were purified as homodimers, and biochemical analysis confirmed Ugd activity, but revealed distinct expression and enzymic properties, indicating different roles for the two Ugd proteins in vivo.

The B. cenocepacia genome (Holden et al., 2009) contains three predicted ugd genes, designated $u g d_{B C A L 2946}$, $u g d_{B C A M 0855}$ and $u g d_{B C A M 2034}$ (gene designations correspond to the Sanger Centre annotation of the strain J2315 genome, http://www.sanger.ac.uk/Projects/B_cenocepacia/, where BCAL denotes genes in the large chromosome and BCAM genes in the mid-size chromosome). In this study, we examined in detail the function of these genes and show that only $u g d_{B C A L 2946}$ is required for resistance to polymyxin B (pmB), while the combination of $u g d_{B C A L 2946}$ and $u g d_{B C A M 0855}$ is required for bacterial survival. We purified $\mathrm{Ugd}_{\mathrm{BCAL2946}}, \mathrm{Ugd}_{\mathrm{BCAM} 0855}$ and $\operatorname{Ugd}_{\text {BCAM2034 }}$ but only the recombinant forms of $\mathrm{Ugd}_{\mathrm{BCAL} 2946}$ and $\mathrm{Ugd}_{\mathrm{BCAM} 0855}$ possess Ugd activity with similar substrate reaction kinetics. Finally, we show that in cells the number of RNA transcripts of $u g d_{B C A L 2946}$ is substantially higher than either $u g d_{B C A M 0855}$ or $u g d_{B C A M 2034}$.

\section{METHODS}

Reagents. Unless otherwise noted all chemicals and antibiotics, restriction endonucleases and DNA polymerases were purchased from Sigma-Aldrich, Roche Diagnostics and Qiagen, respectively.

Bacterial strains and culture conditions. Strains and plasmids used in this study are described in Supplementary Table S1, available with the online version of this paper. B. cenocepacia and Escherichia coli strains were routinely cultured at $37{ }^{\circ} \mathrm{C}$ either in Luria Broth (LB) supplemented with $1.6 \%$ (w/v) Bacto Agar (Becton Dickinson) or in liquid LB. When required, trimethoprim or tetracycline was added at a final concentration of $100 \mu \mathrm{g} \mathrm{ml}^{-1}$ for selection of B. cenocepacia strains, and at $50 \mu \mathrm{g} \mathrm{ml}^{-1}$ and $20 \mu \mathrm{g} \mathrm{ml}^{-1}$, respectively, for selection of E. coli strains. Kanamycin and gentamicin were used at $40 \mu \mathrm{g} \mathrm{ml}^{-1}$ and $50 \mu \mathrm{g} \mathrm{ml}^{-1}$, respectively.

Mutagenesis and cloning. A complete description of the mutagenesis and cloning experiments can be found in Supplementary Methods and the primers used are listed in Supplementary Table S2. To inactivate the putative ugd genes, suicide plasmids containing internal fragments of each ugd gene were created. The fragments were PCR amplified, restriction enzyme digested, ligated into the plasmid pGPlox (Table S1), used to transform E. coli SY327 (Miller \& Mekalanos, 1988), and confirmed by colony PCR and restriction digest. The resulting plasmids - pSL23 (ugd $\left.d_{B C A L 2946}\right)$, pSL29 $\left(u g d_{B C A M 2034}\right)$ and pSL31 $\left(u g d_{B C A M 0855}\right)$ - were transferred into $B$. cenocepacia strain K56-2 (Mahenthiralingam et al., 2000) by triparental mating with the pRK2013 helper plasmid (Figurski \& Helinski, 1979). Exconjugants were screened for plasmid insertion into the correct location by PCR and Southern blot hybridization. The resulting mutants were named SAL8 $\left(u g d_{B C A L 2946}::\right.$ pSL23), SAL12 $\left(u g d_{B C A M 2034}::\right.$ pSL29) and SAL15 $\left(u g d_{B C A L 0855}::\right.$ pSL31).

To construct an unmarked $u g d_{B C A M 0855}$ deletion mutant, two fragments of this gene were PCR amplified, restriction enzyme digested, ligated as a triple ligation into pGPI-SceI (Flannagan et al., 2008), screened as described above, and the resulting plasmid, pSL43, was transferred to K56-2. Putative mutants (SAL22) were screened by PCR for recombination of the plasmid into the chromosome. To delete the backbone of pSL43 from the chromosome, pDAI-SceI (Flannagan et al., 2008) was introduced into SAL22, and this resulted in the isolation of strain SAL23, which carries a 986 bp deletion removing most of $u g d_{B C A M 0855}$. pDAI-SceI was cured from SAL23 by serial passage in the absence of tetracycline for 1 week. The final mutant construct was confirmed by Southern blot hybridization.

Plasmids for the conditional mutagenesis of hldA and $u g d_{B C A L 2946}$ were constructed as described above with fragments corresponding to the $5^{\prime}$ ends of the two genes cloned into the plasmid pSC201 (Ortega et al., 2007), resulting in plasmids pSL26 (hldA) and pSL27 $\left(u_{g} d_{B C A L 2946}\right)$. These plasmids were transferred into SAL23, resulting in strains SAL25 (conditional hldA) and SAL26 (conditional $\left.u g d_{B C A L 2946}\right)$. A conditional $u g d_{B C A L 2946}$ mutant in the K56-2 background (SAL10), also constructed with pSL27, was previously described (Ortega et al., 2007).

For complementation experiments each of the putative ugd genes was cloned into pDA17 (Aubert et al., 2008). Plasmids were confirmed as described above, inserts were verified by sequencing (Robarts Research Institute DNA Sequencing Facility, London, ON, Canada), and the resulting plasmids were named pSL37 ( $\left.u g d_{B C A L 2946}\right), p S L 38$ $\left(u g d_{B C A M 2034}\right)$ and pSL39 $\left(u g d_{B C A M 0855}\right)$.

For expression and purification of the Ugd proteins, the $B$. cenocepacia J2315 ugd $d_{B C A L 2946}, u g d_{B C A M 0855}$ and $u g d_{B C A M 2034}$ genes were PCR amplified, cloned using the pGEM-T Easy vector system (Promega), and sequenced. Genes were liberated by restriction enzyme digest, ligated into pET28a (Novagen), and used to transform 
E. coli Top10 cells. The resulting plasmids were confirmed by restriction digests and named $\mathrm{pJB1}\left(\mathrm{pET} 28 \mathrm{a} / u g d_{B C A L 2946}\right), \mathrm{pJB} 2$ $\left(\mathrm{pET} 28 \mathrm{a} / u g d_{B C A M 0855}\right)$ and $\mathrm{pJB} 3\left(\mathrm{pET} 28 \mathrm{a} / u g d_{B C A M 2034}\right)$, with each ugd expressed with an $\mathrm{N}$-terminal $\mathrm{His}_{6}$ fusion tag.

Growth curves. Cells were cultured overnight to stationary phase and then diluted to an $\mathrm{OD}_{600}$ of 0.05 in LB. Cultures were aliquoted to 100 -well honeycomb plates in $300 \mu \mathrm{l}$ volumes. Plates were incubated in a Bioscreen $\mathrm{C}$ automated growth curve reader at $37{ }^{\circ} \mathrm{C}$ with constant, low shaking for $24 \mathrm{~h}$ with $\mathrm{OD}_{600}$ readings taken every hour. For growth curves with $\mathrm{pmB}$, cells were diluted to approximately $2 \times 10^{5}$ c.f.u. $\mathrm{ml}^{-1}$ in LB. Then $10 \times$ stock solutions of $\mathrm{pmB}$ dissolved in $0.2 \%(\mathrm{w} / \mathrm{v}) \mathrm{BSA}+0.02 \%(\mathrm{v} / \mathrm{v})$ acetic acid were added to cells to give final concentrations of $\mathrm{pmB}$ ranging from 16 to $1024 \mu \mathrm{g} \mathrm{ml}^{-1}$ in twofold increments. Cells were also treated with the pmB diluent indicated above as a vehicle control. Triplicate $300 \mu \mathrm{l}$ aliquots of the cells with either vehicle control or the various concentrations of $\mathrm{pmB}$ were incubated in the Bioscreen $\mathrm{C}$ automated growth curve reader, as described above, for $18 \mathrm{~h}$. $\mathrm{MIC}_{50}$ values reported are the mode of three independent experiments. An assay for growth of conditional mutants was performed as previously described (Ortega et al., 2007). Expression of putative essential genes was repressed with $1.0 \%(\mathrm{w} / \mathrm{v})$ glucose and induced with $1.0 \%(\mathrm{w} / \mathrm{v})$ rhamnose.

LPS extraction and analysis. LPS samples were prepared and analysed as previously described (Hitchcock \& Brown, 1983; Loutet et al., 2006).

Western blotting. Cells were grown overnight in liquid LB with appropriate antibiotics. A volume of culture equivalent to $1 \mathrm{ml}$ at an $\mathrm{OD}_{600}$ of 0.2 was centrifuged for $1 \mathrm{~min}$ at $8000 \mathrm{~g}$, cells were resuspended in $20 \mu \mathrm{H}_{2} \mathrm{O}$ and $10 \mu \mathrm{l}$ of $3 \times$ loading dye, and boiled for $10 \mathrm{~min}$. Aliquots $(15 \mu \mathrm{l})$ of boiled samples were separated by gel electrophoresis using $14 \%(\mathrm{w} / \mathrm{v})$ SDS-polyacrylamide gels and transferred to a nitrocellulose membrane. The membrane was washed briefly with $\mathrm{H}_{2} \mathrm{O}$ and stained with a solution of $0.1 \%(\mathrm{w} / \mathrm{v})$ Ponceau S in $5 \%(\mathrm{v} / \mathrm{v})$ acetic acid to confirm the transfer of equal amounts of protein to the membrane in each lane. The membrane was rinsed with Tris-buffered saline, pH 7.5 (TBS) to remove Ponceau S stain and then blocked for $2 \mathrm{~h}$ with $10 \%(\mathrm{v} / \mathrm{v})$ Western blocking reagent (Roche) in TBS at room temperature and incubated with murine anti-FLAG M2 monoclonal antibody diluted 1:10000 overnight at $4{ }^{\circ} \mathrm{C}$. The membrane was incubated at room temperature for $2 \mathrm{~h}$ with goat anti-mouse IgG antibody conjugated to Alexa Fluor 680 (Molecular Probes) diluted 1:20000. Proteins were visualized using a Licor Infrared Imaging System with Odyssey software version 2.1.

Purification of recombinant Ugd proteins. To prepare recombinant $\mathrm{Ugd}_{\text {BCAL2946 }}$ and $\mathrm{Ugd}_{\text {BCAM0855 }}$ proteins for biochemical analysis, a large-scale culture (4 $1 \mathrm{LB}$ with kanamycin) was performed with $E$. coli HMS 174 (DE3) transformed with pJB1 or pJB2. Each batch was grown to an $\mathrm{OD}_{600}$ of 0.6 , and induced with $0.5 \mathrm{mM}$ IPTG for $3 \mathrm{~h}$ at $37{ }^{\circ} \mathrm{C}$ with shaking. Both $\operatorname{Ugd}_{\text {BCAL2946 }}$ and $\mathrm{Ugd}_{\text {BCAM0855 }}$ were highly overexpressed in soluble forms and cell-free extracts were prepared by sonic disruption of the E. coli cell paste. The enzymes were isolated from ultrafiltered cell-free extracts by FPLC (ÄKTA Basic instrument) using a $5 \mathrm{ml}$ HisTrap column (GE Healthcare). The binding buffer consisted of $20 \mathrm{mM}$ Tris, $500 \mathrm{mM} \mathrm{NaCl}, 5 \mathrm{mM}$ imidazole, $\mathrm{pH} 7.5$, and the elution buffer was identical except that it contained $500 \mathrm{mM}$ imidazole. The eluted His-tagged Ugd proteins were judged $>90 \%$ pure after this step. The enzymes were dialysed against $150 \mathrm{mM} \mathrm{NaCl}$

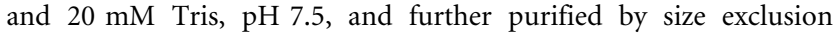
chromatography using a HiPrep 26/60 Sephacryl S-200 column (GE Healthcare). The calibrated column was equilibrated with $150 \mathrm{mM}$ $\mathrm{NaCl}$ and $20 \mathrm{mM}$ Tris, $\mathrm{pH}$ 7.5. The molecular masses of the Ugd proteins, estimated from their column elution volumes and by non- denaturing gel electrophoresis, were consistent with dimers (data not shown). The subunit molecular masses were confirmed by electrospray-mass spectrometry (ESI-MS) and were within $0.1 \%$ of the theoretical values (data not shown). The protein concentration was determined by a BCA assay (Pierce) and a typical yield was $\sim 3 \mathrm{mg}$ Ugd per litre of E. coli culture.

To prepare recombinant $\mathrm{Ugd}_{\mathrm{BCAM} 2034}$, a large-scale culture $(41 \mathrm{LB}$ with kanamycin) was performed with E. coli BL21 (DE3) transformed with $\mathrm{pJB}$. Each batch was grown to an $\mathrm{OD}_{600}$ of 0.6 , and induced by addition of $0.2 \mathrm{mM}$ IPTG for $16 \mathrm{~h}$ at $15{ }^{\circ} \mathrm{C}$ with shaking. To solubilize $\operatorname{Ugd}_{\text {BCAM2034 }}$ for purification, the pellet was resuspended and homogenized in $5 \mathrm{ml}$ binding buffer containing $25 \%(\mathrm{w} / \mathrm{v})$ sucrose, $1 \mathrm{mM}$ EDTA and a protease inhibitor tablet per gram of cell pellet. Thirty mg lysozyme, $5 \mu \mathrm{LNase}$ and $5 \mathrm{mM} \mathrm{MgCl} 2$ were added and the cell paste was left to stir for $1 \mathrm{~h}$ at $4{ }^{\circ} \mathrm{C}$. A cell-free extract was prepared by sonic disruption of the E. coli cell paste, which was incubated with $1 \%(\mathrm{w} / \mathrm{v})$ dodecylmaltoside (DDM) and $20 \%(\mathrm{v} / \mathrm{v})$ glycerol for $1 \mathrm{~h}$ at $4{ }^{\circ} \mathrm{C}$ with stirring before centrifugation at $25000 \mathrm{~g}$ for $45 \mathrm{~min}$. The supernatant was incubated with equilibrated nickel NTA agar beads (Qiagen) for $3 \mathrm{~h}$. The beads were then washed in elution buffer $[20 \mathrm{mM}$ Tris, $\mathrm{pH} 7.5,500 \mathrm{mM} \mathrm{NaCl}, 0.1 \%(\mathrm{w} / \mathrm{v})$ DDM and $10 \%$ glycerol] with $10 \mathrm{mM}$ imidazole. Protein was eluted in elution buffer containing $20,50,100$ or $200 \mathrm{mM}$ imidazole. The molecular mass of $\mathrm{Ugd}_{\text {BCAM2034 }}$ was estimated from size-exclusion chromatography (as above), ESI-MS and non-denaturing gel electrophoresis (data not shown).

In vitro Ugd activity assay. Ugd oxidizes UDP-glucose to UDPglucuronic acid, and in the process also reduces 2 mol NAD ${ }^{+}$to $2 \mathrm{~mol} \mathrm{NADH}$. The absorption coefficient of NADH is $6.220 \mathrm{mM}^{-1}$ $\mathrm{cm}^{-1}$ at $340 \mathrm{~nm}$. A standard Ugd activity assay was set up using $200 \mu \mathrm{l} \mathrm{H}_{2} \mathrm{O}, 100 \mu \mathrm{l}$ purified Ugd $\left(1 \mathrm{mg} \mathrm{ml}{ }^{-1}\right), 200 \mu \mathrm{l}$ buffer (100 mM Tris, pH 7.5), $250 \mu \mathrm{NAD}^{+}(10 \mathrm{mM}$; Roche $)$ at $25^{\circ} \mathrm{C}$. The reaction was initiated by the addition of $250 \mu$ l UDP-glucose ( $1 \mathrm{mM}$; Calbiochem) and the production of NADH was monitored at $340 \mathrm{~nm}$ on a Cary $50 \mathrm{UV}$ visible spectrophotometer (Varian). Initial velocities were determined for UDP-glucose using concentrations ranging from 0 to $0.25 \mathrm{mM}$, and for $\mathrm{NAD}^{+}$using concentrations ranging from 0 to $2.5 \mathrm{mM}$. To determine kinetic constants, one substrate was held constant at the maximum concentration, while the other was varied. The kinetic parameters $\left(k_{\text {cat }}, K_{\mathrm{m}}, V_{\max }\right)$ were determined by non-linear regression from $V=V_{\max }[\mathrm{S}]^{h} /\left([\mathrm{S}]^{h}+K_{\mathrm{m}}{ }^{h}\right)$ using Origin 6.1 software. Substrate specificity was investigated by replacing the substrate UDP-glucose with either UDP-galactose, UDP-acetylglucosamine or GDP-mannose (Calbiochem), and performing the standard assay.

Real-time PCR analysis. B. cenocepacia strain K56-2 was grown overnight in liquid $\mathrm{LB}$, diluted to an $\mathrm{OD}_{600}$ of 0.1 and grown to a final $\mathrm{OD}_{600}$ between 0.5 and 0.7 . RNA was prepared from approximately $5 \times 10^{8}$ c.f.u. with the Ribo-Pure Bacteria kit (Ambion) according to the manufacturer's instructions. RNA was treated with DNase I (Ambion) and the concentration of RNA was determined with an ND-1000 spectrophotometer (NanoDrop Technologies). One microgram of RNA was converted to cDNA using Transcriptor Reverse Transcriptase (Roche) in a reaction volume of $30 \mu$ with reverse primers 3136 (hisD), $3246\left(u g d_{B C A M 0855}\right), 3247\left(u g d_{B C A L 2946}\right)$ and 3364 ( $\left.u g d_{B C A M 2034}\right)$ according to the manufacturer's instructions and supplemented with Protector RNase Inhibitor (Roche), $0.5 \times \mathrm{Q}$ solution (Qiagen) and $10 \%(\mathrm{v} / \mathrm{v})$ DMSO. A second reaction containing nuclease-free water (Qiagen) instead of Transcriptor Reverse Transcriptase was included as a negative control.

The real-time PCRs were conducted using the Rotor-Gene 6000 (Corbett Life Science) in final reaction volumes of $20 \mu$ l. Reactions of $18 \mu \mathrm{l}$, containing FastStart SYBR Green (Roche), primer pairs $3247 / 3255\left(u g d_{B C A L 2946}\right), 3361 / 3364 \quad\left(u g d_{B C A M 2034}\right), 3246 / 3248$ 
$\left(u g d_{B C A M 0855}\right)$ or $3136 / 3143$ (hisD), and nuclease-free water were prepared and to these $2 \mu \mathrm{l}$ of the reverse transcription reactions was added in triplicate. Negative controls were $2 \mu \mathrm{l}$ of the reverse transcription reaction done without Transcriptor Reverse Transcriptase and $2 \mu \mathrm{l}$ of nuclease-free water. The segment of each gene analysed was also amplified from chromosomal DNA and used in standard curve reactions containing $10^{6}, 10^{5}, 10^{4}, 10^{3}$ and $10^{2}$ copies of the PCR products per reaction. The thermal cycling conditions were $95{ }^{\circ} \mathrm{C}$ for $10 \mathrm{~min}, 35$ cycles at $95{ }^{\circ} \mathrm{C}$ for $10 \mathrm{~s}, 60{ }^{\circ} \mathrm{C}$ for $15 \mathrm{~s}$, and $72{ }^{\circ} \mathrm{C}$ for $30 \mathrm{~s}$. Data were acquired on the green channel at the end of each cycle. After the PCR a melt curve was obtained by increasing the temperature from $72{ }^{\circ} \mathrm{C}$ to $95{ }^{\circ} \mathrm{C}$ in $1{ }^{\circ} \mathrm{C}$ increments, with data acquired on the green channel at each degree. Data were analysed using the Rotor-Gene 6000 software provided by the manufacturer. For each analysed gene, the number of copies per reaction was quantified by comparison to the standard curve and adjusted based on the PCR efficiency calculated from the standard curve. A mean value from three replicates was calculated for the internal control hisD. Each replicate value of each ugd gene was divided by the mean of the his $D$ results in order to obtain a ratio of each value to hisD.

Statistical analyses. Statistical analyses were done with GraphPad Prism 4.

\section{RESULTS}

\section{Identification of three putative ugd genes in $B$. cenocepacia}

A TBLASTN analysis of the genome of $B$. cenocepacia strain J2315 (Holden et al., 2009) using the $P$. aeruginosa strain PAO1 Ugd (PA2022; accession no. NP_250712) gave three high scoring hits: $u g d_{B C A L 2946}, u g d_{B C A M 0855}$ and $u g d_{B C A M 2034}$. The presence of these genes was also confirmed in strain K56-2, which is clonally related to J2315 (Mahenthiralingam et al., 2000), but much more amenable to genetic manipulation. The chromosomal arrangements of these genes are shown in Fig. 1(a). $u g d_{B C A L 2946}$ is directly upstream of $h l d A$ and $h l d D$ within a six-gene cluster. hldA and hldD encode proteins required for the synthesis of L-glycero-D-manno-heptose, a critical residue of the LPS inner-core oligosaccharide (Loutet et al., 2006). $u g d_{B C A M 0855}$, annotated as bceC by Moreira et al. (2003), is in a ten-gene cluster (the final five genes of which are not depicted in Fig. 1a) that plays a role in exopolysaccharide synthesis in B. cepacia (Moreira et al., 2003). This exopolysaccharide is not produced in $B$. cenocepacia strains J2315 or K56-2 due to the presence of transposable insertion elements within other genes of this cluster (M. S. Saldías \& M. A. Valvano, unpublished data). $u g d_{B C A M 2034}$ is in a four-gene cluster that contains two open reading frames similar to galE (UDP-galactose 4epimerase) as well as a predicted glycosyltransferase. The sequences of the three predicted ugd genes in strain K56-2 are identical to those in the sequenced J2315 strain.

The three loci $u g d_{B C A L 2946}, u g d_{B C A M 0855}$ and $u g d_{B C A M 2034}$ are predicted to encode proteins sharing, respectively, $53 \%, 52 \%$ and $39 \%$ amino acid sequence identity with $P$. aeruginosa $\mathrm{PA} 2022$. The predicted proteins $\mathrm{Ugd}_{\mathrm{BCAL} 2946}$ and $\mathrm{Ugd}_{\text {BCAM0855 }}$ share $74 \%$ amino acid sequence identity. The predicted $\operatorname{Ugd}_{\text {BCAM2034 }}$ shares $44 \%$ and $45 \%$ amino acid sequence identity with $\operatorname{Ugd}_{\text {BCAL2946 }}$ and $\operatorname{Ugd}_{\text {BCAM0855, }}$, respectively. Fig. 1(b) shows a CLUSTAL W alignment of the three predicted Ugd proteins of $B$. cenocepacia, $P$. aeruginosa Ugd PA2022 and Streptococcus pyogenes Ugd (accession no. AAA26899). Despite low pair-wise sequence identity ( $21 \%$ ) with the S. pyogenes Ugd, for which highresolution crystal structures are available (Protein Data Bank, accession nos 1DLI and 1DLJ) (Campbell et al., 2000), each of the three predicted Ugd proteins contains a predicted Rossmann fold for $\mathrm{NAD}^{+}$binding (Rossman, 1981) at the $\mathrm{N}$ terminus, and residues involved in the catalytic mechanism (Campbell et al., 2000), such as Cys260 involved in thioester formation and Arg244 involved in UDP-sugar specificity, are conserved (equival-

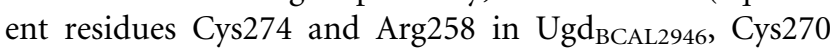
and $\operatorname{Arg} 254$ in $\operatorname{Ugd}_{\text {BCAM0855, }}$, and Cys266 and Arg250 in $\operatorname{Ugd}_{\text {BCAM2034). }}$.

\section{A mutation in $u g d_{B C A L 2946}$ confers sensitivity to polymyxin B}

To assess the function of the candidate ugd genes, three mutant strains were constructed, each with a different putative ugd gene inactivated by insertional mutagenesis: SAL8 ( $u g d_{B C A L 2946}:$ pSL23), SAL12 (ugd $d_{\text {BCAM2034: }}$ :pSL29) and SAL15 $\left(u g d_{B C A M 0855}:\right.$ :pSL31). SAL12 and SAL15 grew similarly to the parental strain, K56-2 (Fig. 2). In contrast, SAL8 exhibited a slightly slower growth rate in exponential phase, but eventually reached the same cell density as K562, SAL12 and SAL15 (Fig. 2). There were no detectable differences in the LPS profiles of mutant strains compared to that of the parental K56-2 when LPS was prepared from cells, separated by gel electrophoresis, and stained with silver (data not shown); however, detection of subtle changes to LPS structure may require a more sensitive method of analysis. The ugd mutants were tested for their ability to grow in LB medium containing $\mathrm{pmB}$ at a concentration of $1024 \mu \mathrm{g} \mathrm{ml}^{-1}$. Fig. 3(a) shows that the growth of SAL8 was significantly impaired at this concentration of $\mathrm{pmB}$, in comparison to $\mathrm{K} 56-2$ and the other two mutants. In vehicle control incubations, K56-2, SAL12 and SAL15 all grew equivalently and the growth of SAL8 was slightly slower in the exponential phase of growth (Fig. 3a inset), similar to the results shown above with $\mathrm{LB}$ alone. The $\mathrm{MIC}_{50}$ values for $\mathrm{pmB}$ were also calculated for all the strains. For K56-2, SAL12 and SAL15 the $\mathrm{MIC}_{50}$ values for $\mathrm{pmB}$ were all greater than $1024 \mu \mathrm{g}$ $\mathrm{ml}^{-1}$ (the highest concentration tested). For SAL8, the $\mathrm{MIC}_{50}$ value for $\mathrm{pmB}$ was $128 \mu \mathrm{g} \mathrm{ml}^{-1}$.

Next, SAL8 was transformed with a series of plasmids, each containing a different putative ugd gene fused to the FLAG epitope at the 3' end of the gene. Growth of SAL8(pDA17) containing a vector control or SAL8(pSL38) encoding $u g d_{\text {BCAM } 2034}$ was poor in $128 \mu \mathrm{g} \mathrm{ml}^{-1} \mathrm{pmB}$ (Fig. 3b). In fact, the plasmids actually appeared to exacerbate the 
(a)
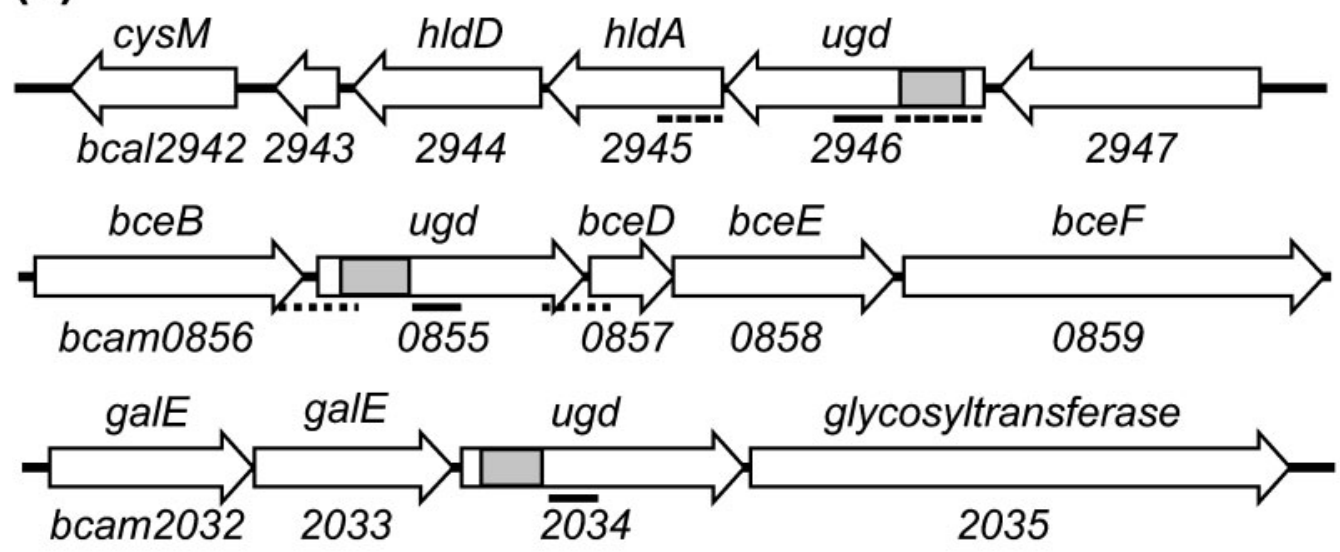

(b)

BCAL2946 :

BCAM0855 :

- MNLTII

PA2022:

PA2022:--NRLCVI

Spyougd

2033

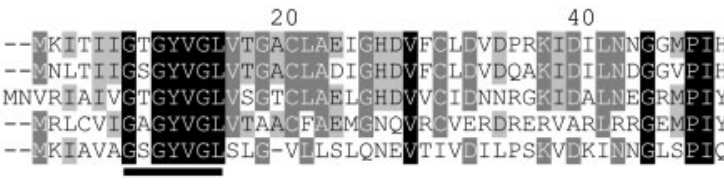

40

20

60

80
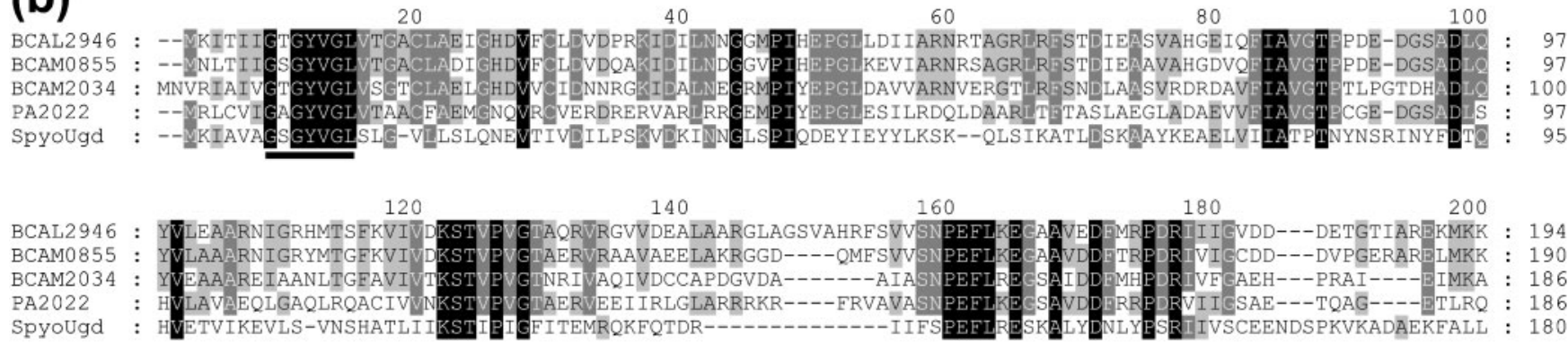

SpyoUgd : HVETVIKEVLS-VNSHATLIIKSTIGIGFITEMRQKFQTDR----------IIFSPEFLRESKGLYDNLYESRIIVSCEENDSPKVKADAEKFALL : 180
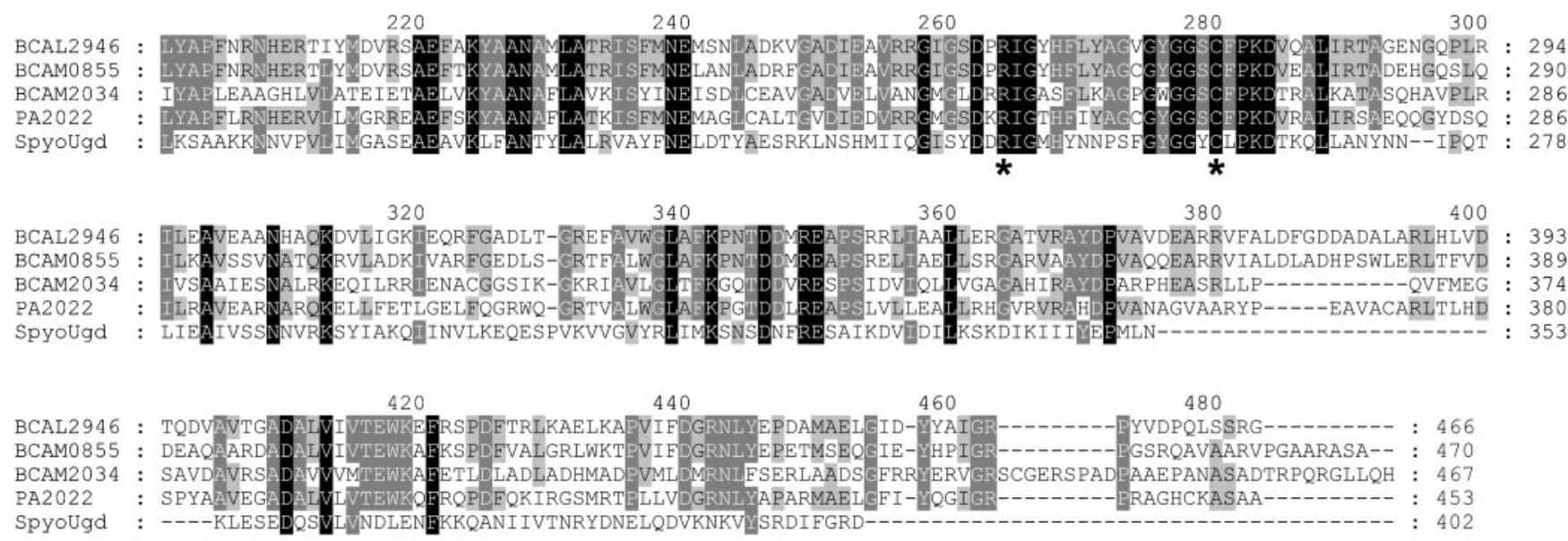

Fig. 1. Identification and chromosomal arrangement of putative ugd genes. (a) Each ugd gene is schematically depicted with neighbouring genes. The nomenclature below each gene is that used in the annotation of the sequenced genome of $B$. cenocepacia strain J2315. Designations above the genes are based on either TBLASTX analysis or previous publications (Iwanicka-Nowicka et al., 2007; Loutet et al., 2006; Moreira et al., 2003). The grey bars within the ugd genes represent the internal fragments that were cloned into the ugd mutagenesis plasmids (pSL23, pSL29 and pSL31 for ugd $B$ CAL2946, $u_{\text {GCAM2O34 }}$ and $u g d_{B C A M 0855}$, respectively). The dashed lines below $h / d A$ and $u g d_{B C A L 2946}$ represent the PCR fragments used to generate plasmids for conditional mutagenesis (pSL26 and pSL27 for $h / d A$ and ugd $d_{B C A L 2946}$, respectively). The dotted lines below $u g d_{B C A M O 855}$ and its neighbouring genes represent the two fragments that were cloned into the plasmid (pSL43) used for unmarked mutagenesis of $u g d_{B C A M 0855}$. The solid lines below each ugd gene represent the regions analysed by realtime PCR. (b) CLUSTAL W alignment of the three putative Ugd proteins of B. cenocepacia, P. aeruginosa PA2022 and Ugd from S. pyogenes. Residues conserved in all five proteins, four of the five, or three of the five are highlighted in black, dark grey and light grey, respectively. The line below the alignment indicates the conserved GXGXXG motif of the Rossmann fold required for NAD binding. Asterisks denote residues Arg-244 and Cys-260 of S. pyogenes Ugd shown to be important for catalysis. 


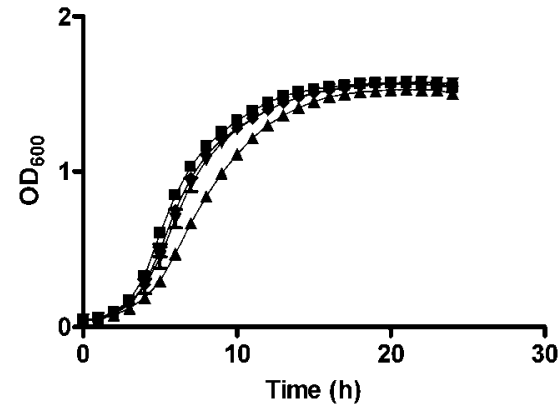

Fig. 2. B. cenocepacia $\mathrm{K} 56-2$ and the panel of ugd mutants grow

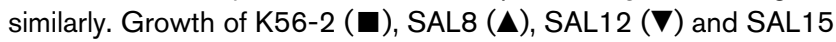
$(\diamond)$ was monitored in a Bioscreen $C$ automated growth curve reader for $24 \mathrm{~h}$. Shown are the means of data from three independent experiments done in triplicate; error bars denote the standard error of the mean.

sensitivity to pmB in SAL8 since growth was impaired by $>95 \%$ at this concentration of pmB. The growth of SAL8 transformed with pSL37 $\left(u g d_{B C A L 2946}\right)$ after $18 \mathrm{~h}$ was not statistically different in the presence or absence of $128 \mu \mathrm{g}$ $\mathrm{pmB} \mathrm{ml} \mathrm{m}^{-1}$, similar to the growth of K56-2 under these conditions. SAL8 transformed with pSL39 ( ugd $_{\text {BCAM0855 }}$ ) regained in part the ability to grow in the presence of $128 \mu \mathrm{g}$ $\mathrm{pmB} \mathrm{ml} \mathrm{m}^{-1}$. Western blot analysis showed that all three putative Ugd proteins were expressed in SAL8 (Fig. 4), although not to the same levels. The predicted masses for Ugd-FLAG $\mathrm{BCAL2946}_{\text {, Ugd-FLAG }}$ BCAM2034, and UgdFLAG $_{\text {BCAM0855 }}$ are $51.7 \mathrm{kDa}, 50.9 \mathrm{kDa}$ and $52.1 \mathrm{kDa}$, respectively. Bands indicated with arrows correspond approximately to the predicted sizes. In addition, we observed numerous faster-migrating bands for the UgdFLAG constructs that were consistent between experiments. These bands were interpreted as degradation products due to proteolytic cleavage either in the cell or during the sample preparation. Ponceau $S$ staining of the membrane before Western blotting indicated that equal amounts of protein were transferred to the membrane in each lane (data not shown). Similar complementation results were obtained with a series of vectors expressing Ugd proteins not fused to the FLAG epitope (data not shown). Together, these experiments indicate that of the three putative ugd genes, only $u g d_{B C A L 2946}$ is required for the full resistance of $B$. cenocepacia strain K56-2 to $\mathrm{pmB}$ and also that the protein encoded by $u g d_{B C A M 0855}$ can compensate for the function of the protein encoded by $u g d_{B C A L 2946}$.

\section{The combined activity of $\mathrm{Ugd}_{\mathrm{BCAL2946}}$ and $\mathrm{Ugd}_{\mathrm{BCAM0855}}$ is essential for viability}

Due to the role of Ugd in the synthesis of UDP-Ara4N, we hypothesized that the combined Ugd activity of $B$. cenocepacia is essential for viability of the organism. Based on the results described above, we predicted that the combination of $u g d_{B C A L 2946}$ and $u g d_{B C A M 0855}$ would be
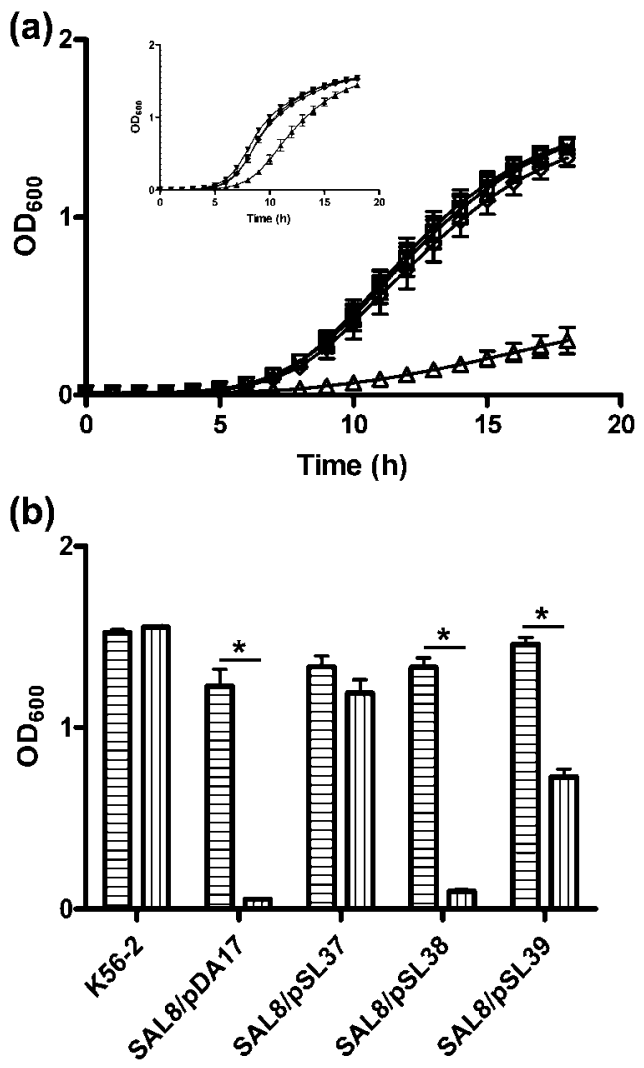

Fig. 3. SAL8 is the only ugd mutant that is sensitive to pmB. (a) Growth of K56-2 $(\boldsymbol{\square}, \square), \operatorname{SAL8}(\boldsymbol{\Delta}, \triangle), \operatorname{SAL} 12(\boldsymbol{\nabla}, \nabla)$ and SAL15 $(\diamond, \diamond)$ in either a vehicle control (filled symbols, shown in inset) or $1024 \mu \mathrm{g} \mathrm{pmB} \mathrm{ml} \mathrm{m}^{-1}$ (empty symbols) was monitored for $18 \mathrm{~h}$. (b) End point $\mathrm{OD}_{600}$ of K56-2 and SAL8 with either pDA17 (plasmid control), pSL37 $\left(u g d_{B C A L 2946}\right), p S L 38\left(u g d_{B C A M 2034}\right)$ or pSL39 $\left(u g d_{B C A M 0855}\right)$ grown for $18 \mathrm{~h}$ in either a vehicle control (horizontally striped bars) or $128 \mu \mathrm{g} \mathrm{pmB} \mathrm{ml}{ }^{-1}$ (vertically striped bars). Shown are the mean and standard error of the mean for data from three independent experiments done in triplicate. *, Statistically significant difference $(P<0.05)$ between vehicle control and pmB treatments by unpaired $t$-test.

essential. To test this, a strain containing an unmarked $u g d_{B C A M 0855}$ deletion was created (SAL23). Like SAL15, SAL23 did not show impaired resistance to $\mathrm{pmB}$ (data not shown). SAL23 was then used for the creation of conditional mutants in $u g d_{B C A L 2946}$ (SAL26) and the downstream gene, hldA (SAL25).

These strains were tested for their ability to grow under inducing (rhamnose) and repressing (glucose) conditions. The wild-type strain K56-2 transformed with pSCrhaB2 (to allow for growth in medium supplemented with trimethoprim) grew equally well on plates with either glucose or rhamnose (Fig. 5, first lane). XOA11, a positive control for a conditional mutant of an essential gene required for Ara4N transfer to lipid A, grew well in the presence of rhamnose but growth was substantially impaired in the 


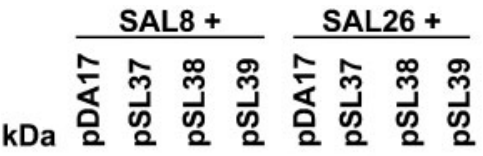

97

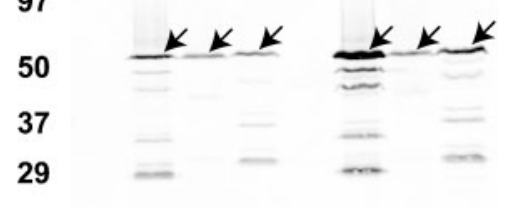

20

Fig. 4. All three Ugd-FLAG constructs are expressed in SAL8 and SAL26. Western blot analysis using anti-FLAG antibodies was done for both SAL8 and SAL26 containing either pDA17 (plasmid control), pSL37 $\left(u g d_{B C A L 2946}\right), p S L 38\left(u g d_{B C A M 2034}\right)$ or pSL39 $\left(u g d_{B C A M 0855}\right)$. Arrows indicate bands that correspond to the fulllength Ugd-FLAG constructs. This is a representative image of three independent experiments.

presence of glucose (Fig. 5, second lane), as previously demonstrated (Ortega et al., 2007). Two negative control strains, SAL10 (a $u g d_{B C A L 2946}$ conditional mutant with an intact $u g d_{B C A M 0855}$ gene) and SAL25 (the conditional hldA mutant lacking $u g d_{B C A M 0855}$ but with $u g d_{B C A L 2946}$ intact) both grew equally well in the presence of either glucose or rhamnose (Fig. 5, third and fourth lanes, respectively). Finally, SAL26, the conditional $u g d_{B C A L 2946}$ mutant lacking an intact $u g d_{B C A M 0855}$ gene, grew well in the presence of rhamnose but like XOA11 its growth was very poor in the presence of glucose (Fig. 5, fifth lane).

Next, experiments were carried out to determine which of the three putative ugd genes could complement the conditional growth defect of SAL26. In the presence of rhamnose, the growth of SAL26 transformed with any of the plasmids was similar to that of untransformed SAL26 cells (Fig. 5, top right panel). However, growth of SAL26 in the presence of glucose improved significantly in cells transformed with either pSL37 or pSL39 but not with pSL38 or the plasmid control, pDA17 (Fig. 5, bottom right panel). Western blot analysis showed that all three UgdFLAG constructs were expressed in SAL26, with protein profiles similar to those in SAL8 (Fig. 4); Ponceau S staining of the membrane showed that there was equal transfer of proteins in each of the lanes (data not shown). Together, these experiments indicate that the combined activity of the proteins encoded by $u g d_{B C A L 2946}$ and $u g d_{B C A M 0855}$ is required for the viability of $B$. cenocepacia.

\section{Ugd $_{\text {BCAL2946 }}$ and Ugd BCAM0855 $_{\text {have similar }}$ reaction kinetics}

To further characterize the proteins encoded by $u g d_{B C A L 2946}, u g d_{B C A M 0855}$ and $u g d_{B C A M 2034}$, the genes were

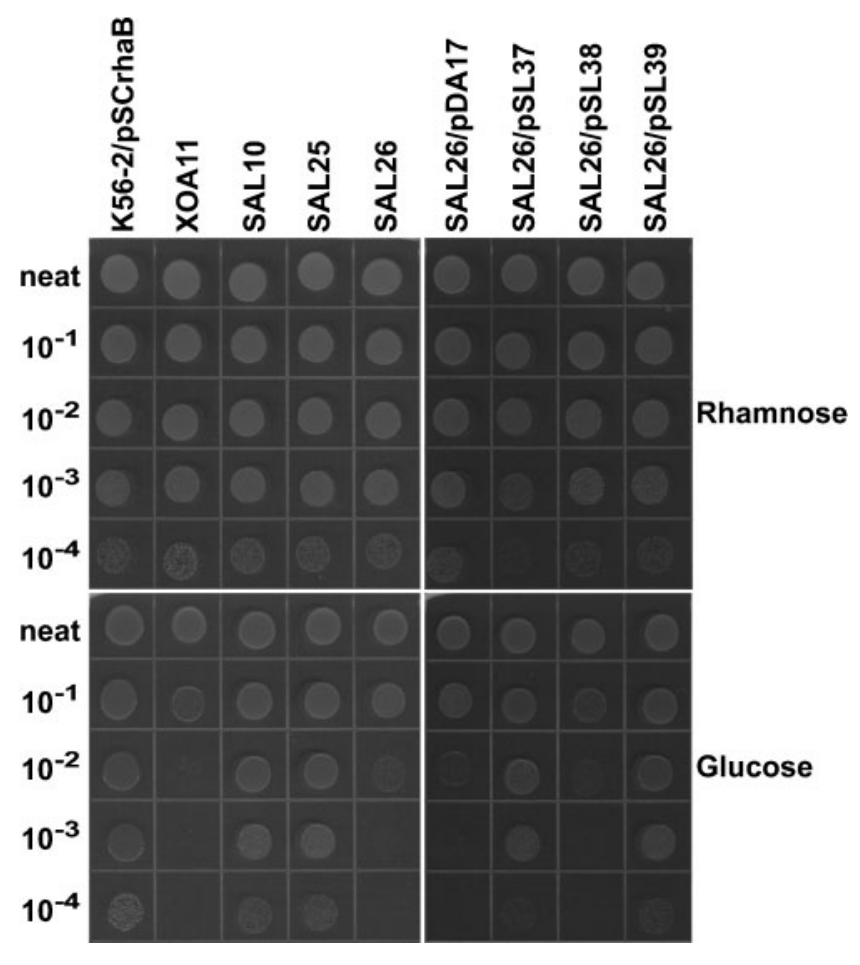

Fig. 5. The combined activity of $\operatorname{Ugd}_{\mathrm{BCAL} 2946}$ and $\mathrm{Ugd}_{\mathrm{BCAM} 0855}$ is essential for viability of $B$. cenocepacia strain K56-2. Left panels: K56-2 with pSCrhaB (for growth of wild-type on agar plates with trimethoprim), XOA11 (positive control for a strain with a conditional mutant in an essential gene), SAL10 (negative control, $u_{\text {gd }} d_{B C A L 2946}$ conditional mutant in the presence of a functional copy of $u g d_{B C A M 0855}$ ), SAL25 (negative control, $\Delta u g d_{B C A M 0855}$ strain with a conditional mutation in $h / d A$, the gene downstream of $\left.u g d_{B C A L 2946}\right)$ and SAL26 ( $\Delta u g d_{B C A M 0855}$ strain with a conditional mutation in $u g d_{B C A L 2946}$ ) were grown overnight, serially diluted, and $10 \mu \mathrm{l}$ drops were plated on media containing either rhamnose (inducing conditions, top panel) or glucose (repressing conditions, bottom panel). Mutants with a conditional lethal phenotype grow well on agar plates with rhamnose but grow much more poorly on glucose. Right panels: growth of SAL26 in the presence of either

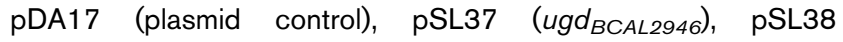
$\left(u g d_{B C A M 2034}\right)$ or pSL39 $\left(u g d_{B C A M 0855}\right)$ under inducing or repressing conditions of chromosomally encoded ugd ${ }_{B C A L 2946}$. Shown is a representative image of three independent experiments.

cloned into a pET28 vector to add an $\mathrm{N}$-terminal $\mathrm{His}_{6}$ tag. $\mathrm{Ugd}_{\text {BCAL2946 }}$ and $\mathrm{Ugd}_{\text {BCAM0855 }}$ were overexpressed in E. coli and purified using nickel affinity and size exclusion chromatography. The $\operatorname{Ugd}_{\text {BCAL2946 }}$ and $\operatorname{Ugd}_{\text {BCAM0855 }}$ proteins were soluble and behaved as homodimers $(\sim 106 \mathrm{kDa})$ with similar elution profiles (data not shown). $\mathrm{Ugd}_{\mathrm{BCAM} 2034}$ was insoluble and required low-temperature induction and an additional solubilization step prior to purification as a mixture of monomer $(\sim 52 \mathrm{kDa})$ and homodimer $(\sim 104 \mathrm{kDa})$ (data not shown). The enzyme assay was based on the Ugd mechanism proposed by 
Campbell et al. (2000) and Ge et al. (2004): UDP-glucose is converted to UDP-glucuronic acid in a two-step oxidation via a covalently bound thioester intermediate. Conversion of this to the final free UDP-glucuronic acid product requires a second mole of $\mathrm{NAD}^{+}$so overall the process reduces two $\mathrm{NAD}^{+}$to two NADH. To determine the kinetic parameters, the initial velocity was calculated by measuring the increase in absorbance at $340 \mathrm{~nm}$, due to the production of NADH, divided by two. The data were fitted by non-linear regression with the Hill equation ( $V=$ $V_{\max }[\mathrm{S}]^{h} /\left([\mathrm{S}]^{h}+K_{\mathrm{m}}{ }^{h}\right)$. The enzyme turnover $\left(k_{\mathrm{cat}}\right)$ and catalytic efficiency $\left(k_{\text {cat }} / K_{\mathrm{m}}\right)$ were calculated from the $V_{\max }$ and $K_{\mathrm{m}}$ values obtained. Both $\operatorname{Ugd}_{\text {BCAL2946 }}$ and Ugd $_{\text {BCAM0855 }}$ showed Ugd activity with very similar kinetic constants (Table 1), while $\operatorname{Ugd}_{\text {BCAM2034 }}$ showed no in vitro activity with UDP-glucose as a substrate To investigate any substrate specificity variation between the Ugd proteins, the spectrophotometric assay was repeated with three additional UDP-sugars (UDP-galactose, UDP-acetylglucosamine and GDP-mannose) that replaced UDP-glucose. None of these molecules were substrates for any of the enzymes (data not shown). From these experiments we conclude that $\mathrm{Ugd}_{\mathrm{BCAL} 2946}$ and $\mathrm{Ugd}_{\mathrm{BCAM} 0855}$ have very similar enzymic activities and confirm biochemically the functional assignment of these proteins as UDP-glucose dehydrogenases.

\section{Expression of $u g d_{B C A L 2946}$ is higher than that of $u g d_{B C A M O 855}$ or $u g d_{B C A M 2034}$}

Since both $\operatorname{Ugd}_{\text {BCAL2946 }}$ and $\operatorname{Ugd}_{\text {BCAM0855 }}$ demonstrated very similar kinetic parameters, we investigated whether these proteins are differentially expressed in vivo. RNA was prepared from B. cenocepacia cells in exponential growth and the number of RNA transcripts of each ugd gene was quantified and compared to the number of transcripts of the constitutively active gene his D. The number of $u g d_{B C A L 2946}$ transcripts was on average 5.4 times and 135 times higher than the number of $u g d_{B C A M 0855}$ or $u g d_{B C A M 2034}$ transcripts, respectively (Fig. 6). Melting curves for each portion of each gene analysed by real-time PCR were similar to the positive controls and there were no detectable differences in band sizes by agarose gel electrophoresis (data not shown), indicating that the products amplified after the reverse transcription reaction were the same as those amplified in the positive controls. These results indicate that $u g d_{B C A L 2946}$ is highly expressed relative to the expression of $u g d_{B C A M 0855}$, while the expression of $u g d_{B C A M 2034}$ under the condition tested (exponential growth) is negligible. These results help to explain why only the mutant defective in $u g d_{B C A L 2946}$ has a phenotype in terms of pmB sensitivity, and also why the double mutant ( $\triangle u g d_{B C A M 0855}, u g d_{B C A L 2946}$ conditional) fails to grow under non-permissive conditions.

\section{DISCUSSION}

We demonstrate here that the proteins encoded by two $B$. cenocepacia genes, $u g d_{B C A L 2946}$ and $u g d_{B C A M 0855}$, possess the predicted dehydrogenase activity, which results in the conversion of UDP-glucose into UDP-glucuronic acid. $\operatorname{Ugd}_{\text {BCAL2946 }}$ and $\operatorname{Ugd}_{\text {BCAM0855 }}$ are efficient catalysts with low micromolar $K_{\mathrm{m}}$ values for UDP-glucose and $\mathrm{NAD}^{+}$ and relatively fast turnover. The similar catalytic profile for these enzymes is not surprising since they show $74 \%$ amino acid sequence identity. The two $P$. aeruginosa Ugd proteins described by Hung et al. (2007) utilized UDPgalactose and UDP- $N$-acetylglucosamine as substrates, but with much lower activity compared with UDP-glucose. However, apart from UDP-glucose, the two B. cenocepacia Ugd proteins did not exhibit any activity when any of the other three UDP-sugar substrates were used. This substrate specificity correlates with the high catalytic efficiency $\left(k_{\mathrm{cat}} / K_{\mathrm{m}}\right)$ of the enzymes, and the similar biochemical profiles of $\operatorname{Ugd}_{\text {BCAL2946 }}$ and $\operatorname{Ugd}_{\text {BCAM0855 }}$ explain why they can compensate each other's function in vivo during complementation assays.

B. cenocepacia is highly resistant to APs and understanding the molecular basis of this resistance is a longstanding goal of our groups. Here, we show that only $u g d_{B C A L 2946}$ is necessary for resistance to the $\mathrm{AP} \mathrm{pmB}$, as the insertional inactivation of this gene led to an eightfold increase in sensitivity to $\mathrm{pmB}$. This phenotype does not appear to be due to a polar effect on hldA and hldD, the two genes downstream of $u g d_{B C A L 2946}$, based on two experimental

Table 1. Kinetic parameters of $\operatorname{Ugd}_{\mathrm{BCAL2946}}$ and $\mathrm{Ugd}_{\mathrm{BCAM} 0855}$

Parameters were determined by non-linear regression from $V=V_{\max }[\mathrm{S}]^{h} /\left([\mathrm{S}]^{h}+K_{\mathrm{m}}{ }^{h}\right.$ using Origin6.1 software.

\begin{tabular}{|c|c|c|c|c|c|}
\hline Protein & $\begin{array}{c}V_{\max } \\
\left(\mathrm{nmol} \mathrm{min}^{-1}\right)\end{array}$ & $K_{\mathrm{m}}(\mathbf{m M})$ & $h$ & $k_{\text {cat }}\left(\min ^{-1}\right)$ & $\begin{array}{c}k_{\mathrm{cat}} / K_{\mathrm{m}} \\
\left(\mathrm{mM}^{-1} \min ^{-1}\right)\end{array}$ \\
\hline & \multicolumn{5}{|c|}{ UDP-glucose } \\
\hline $\operatorname{Ugd}_{\text {BCAL2946 }}$ & $14.38 \pm 0.73$ & $0.02 \pm 0.01$ & $1.25 \pm 0.16$ & $7.99 \pm 0.13$ & $392.36 \pm 0.37$ \\
\hline $\mathrm{Ugd}_{\text {BCAM } 0855}$ & $13.73 \pm 0.90$ & $0.02 \pm 0.01$ & $\begin{array}{l}1.41 \pm 0.12 \\
\mathrm{NAD}^{+}\end{array}$ & $7.63 \pm 0.15$ & $340.35 \pm 0.10$ \\
\hline $\operatorname{Ugd}_{\text {BCAL2946 }}$ & $16.61 \pm 1.11$ & $0.17 \pm 0.03$ & $1.51 \pm 0.31$ & $9.23 \pm 0.15$ & $53.95 \pm 0.19$ \\
\hline $\operatorname{Ugd}_{\text {BCAM } 0855}$ & $16.88 \pm 1.22$ & $0.21 \pm 0.04$ & $1.50 \pm 0.31$ & $9.38 \pm 0.16$ & $44.50 \pm 0.19$ \\
\hline
\end{tabular}




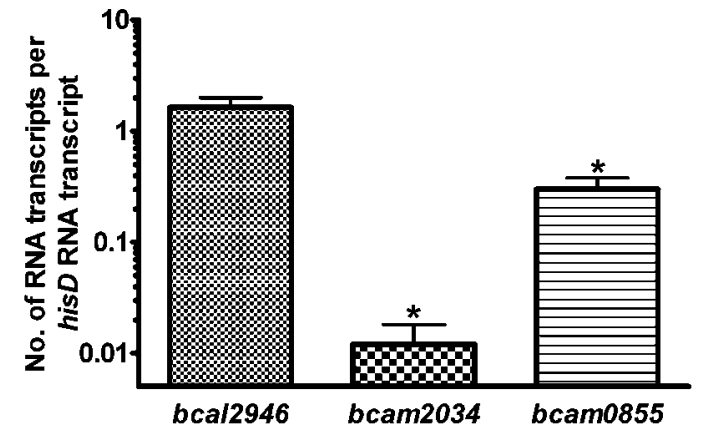

Fig. 6. $u g d_{B C A L 2946}$ is more highly expressed than either $u_{\text {GCAM2O34 }}$ or $u g d_{B C A M 0855}$. Shown are real-time PCR results from three experiments completed in triplicate; error bars represent the standard error of the mean. For each ugd gene the data are standardized to values obtained for the internal control gene, hisD. *, Statistically significant difference $(P<0.01)$ compared to results for ugd $_{B C A L 2946}$ by unpaired $t$-test.

observations: (i) the sensitivity can be restored in trans when $u g d_{B C A L 2946}$ is expressed from a plasmid, and (ii) disruption of hldA and hldD has a profound effect on the structure of the LPS molecule (Loutet et al., 2006), which we did not observe in the $u g d_{B C A L 2946}$ mutant. In fact, no differences were found in the LPS profiles of any of the $u g d$ mutants compared to the LPS profile of the parental strain, although we cannot rule out subtle modifications in the LPS molecule that would require a more detailed analysis, currently under way in our laboratories. The pmB-sensitive phenotype of the $u g d_{B C A L 2946}$ mutant was also complemented by a plasmid-encoded $u g d_{B C A M 0855}$ but not by $u g d_{B C A M 2034}$. The lack of complementation by $u g d_{B C A M 2034}$ was not due to lack of protein expression since all three ugd genes revealed a polypeptide of the expected molecular mass when cloned in a plasmid and expressed as proteinFLAG fusions. Also, lack of complementation was not due to the presence of the C-terminal FLAG epitope, since the same results were obtained in experiments using untagged proteins. These data suggest that $\operatorname{Ugd}_{\text {BCAL2946 }}$ accounts for the cellular Ugd activity required for the resistance of $B$. cenocepacia to pmB.

We have previously demonstrated that the synthesis of UDP-Ara4N is essential for the viability of B. cenocepacia (Ortega et al., 2007). Since the conversion of UDP-glucose into UDP-glucuronic acid is an obligatory step for the synthesis of UDP-Ara4N, we reasoned that a mutant lacking both $u g d_{B C A L 2946}$ and $u g d_{B C A M 0855}$ would not be viable. Indeed, a double mutant in which $u g d_{B C A M 0855}$ is deleted and $u g d_{B C A L 2946}$ is conditionally expressed was non-viable under non-permissive conditions. This result suggests that $\mathrm{Ugd}_{\mathrm{BCAL} 2946}$ and $\mathrm{Ugd}_{\mathrm{BCAM} 0855}$ account for the majority of the cellular Ugd activity required for UDPAra4N synthesis.

Studies in other Gram-negative bacterial species have shown that the expression of $u g d$ genes can be complex. In
Salmonella, a variety of regulatory systems control the expression of the ugd gene. In the presence of high $\mathrm{Fe}^{3+}$, ugd expression is upregulated by PmrA, the response regulator of the two-component regulatory system PmrAPmrB (Wösten et al., 2000). Under low $\mathrm{Mg}^{2+}$ conditions, activation of the two-component regulatory system PhoPPhoQ occurs, activated PhoP upregulates expression of another protein, $\mathrm{PmrD}$, which in turn activates the PmrAPmrB system, and ugd expression is upregulated by PmrA (Kox et al., 2000). Finally, the RcsC-YojN-RcsB phosphorelay system can also control the expression of the ugd gene in Salmonella from a second promoter that is independent of PmrA (Mouslim \& Groisman, 2003). A recent study in $P$. aeruginosa demonstrated that this common CF lung pathogen also possesses two ugd genes and that the two genes are differentially expressed (Hung et al., 2007). Hung et al. (2007) showed that in $P$. aeruginosa strain PAO1 the expression of PA3559 was induced under low $\mathrm{Mg}^{2+}$ conditions and that this gene was required for $\mathrm{pmB}$ resistance, while PA2022 was more constitutively expressed and was not required for $\mathrm{pmB}$ resistance. Similar results were obtained for PA3559 by McPhee et al. (2006), who also showed that the promoter of $P A 3559$ has two binding sites each for the PhoP and PmrA proteins of $P$. aeruginosa. With three genes predicted to encode UDP-glucose dehydrogenase, the regulation of Ugd activity may be even more complicated in B. cenocepacia. We have shown that in cells in the exponential growth phase $u g d_{B C A L 2946}$ is more highly expressed than either $u g d_{B C A M 0855}$ or $u g d_{B C A M 2034}$. Little else is known about the regulatory control of expression of $u g d_{B C A L 2946}, u g d_{B C A M 0855}$ and $u g d_{B C A M 2034}$ and it is something we are currently investigating. None of these ugd genes is directly linked to the arn locus in $B$. cenocepacia, which itself has an unusual gene order (Ortega et al., 2007), and this also suggests that there are differences in operon regulation between Burkholderia and other Gram-negative organisms. It is interesting to note that the response regulators of $B$. cenocepacia most similar to the PhoP and PmrA proteins of $P$. aeruginosa and Salmonella are not required for $\mathrm{pmB}$ resistance (Flannagan et al., 2007), which suggests that they are probably not required for expression of at least $u g d_{B C A L 2946}$. B. cenocepacia does, however, contain numerous other twocomponent regulatory systems that could participate in the response to $\mathrm{pmB}$. The finding that $u g d_{B C A L 2946}$ is more highly expressed than the other two ugd genes suggests to us that this difference may account for the fact that sensitivity to $\mathrm{pmB}$ is only seen in the $u g d_{B C A L 2946}$ mutant strain.

We have shown that the protein encoded by $u g d_{B C A M 2034}$ does not appear to be a player in the total cellular Ugd activity: mutation of the gene neither affects $\mathrm{pmB}$ resistance nor is required for the essential synthesis of UDP-Ara $4 \mathrm{~N}$, the gene cannot rescue the pmB sensitivity of SAL8 or the inability of SAL26 to grow under nonpermissive conditions, the gene is poorly expressed in rapidly dividing cells, and the purified form of the protein 
does not have in vitro Ugd activity under the conditions we tested. Further analysis of the protein encoded by BCAM2034 is required before an enzymic function can be assigned to it.

In summary, we have demonstrated that the most highly expressed ugd gene of $B$. cenocepacia is required for resistance to $\mathrm{pmB}$ and that the two most highly expressed genes are required for viability. However, we cannot conclusively state why disruption of $u g d_{B C A L 2946}$ results in increased sensitivity to $\mathrm{pmB}$. We hypothesize that it is due to small decreases in UDP-Ara4N in the LPS molecule of SAL8 at some point in growth; however, it is also possible that UDP-glucuronic acid is required for some other pathway required for $\mathrm{pmB}$ resistance in $B$. cenocepacia. Studies are ongoing in our laboratories to determine why UDP-Ara4N is essential for the survival of B. cenocepacia, where Ara $4 \mathrm{~N}$ is located in the LPS molecule and whether there are changes in the Ara4N content of the LPS molecules of our conditional mutants as well as the LPS molecules of the individual ugd mutants described in this study.

\section{ACKNOWLEDGEMENTS}

We thank Dr J. Parkhill for access to the annotation of the genome sequence of Burkholderia cenocepacia strain J2315 and Dr David J. Clarke for his help with protein analysis. This work was funded by a grant from the Canadian Cystic Fibrosis Foundation (to M. A. V.). A doctoral research award from the Canadian Institutes of Health Research supported S. A. L. M. A. V. holds a Canada Research Chair in Infectious Disease and Microbial Pathogenesis. D. J. C. and J. R. W. G. thank the Cystic Fibrosis Trust (UK) and the Big Lottery Fund for the award of a studentship to S.J.B. via the UK CF Microbiology Consortium.

\section{REFERENCES}

Aaron, S. D., Ferris, W., Henry, D. A., Speert, D. P. \& Macdonald, N. E. (2000). Multiple combination bactericidal antibiotic testing for patients with cystic fibrosis infected with Burkholderia cepacia. Am J Respir Crit Care Med 161, 1206-1212.

Aubert, D. F., Flannagan, R. S. \& Valvano, M. A. (2008). A novel sensor kinase-response regulator hybrid controls biofilm formation and type VI secretion system activity in Burkholderia cenocepacia. Infect Immun 76, 1979-1991.

Bader, M. W., Sanowar, S., Daley, M. E., Schneider, A. R., Cho, U., Xu, W., Klevit, R. E., Le Moual, H. \& Miller, S. I. (2005). Recognition of antimicrobial peptides by a bacterial sensor kinase. Cell 122, 461-472.

Balandreau, J., Viallard, V., Cournoyer, B., Coenye, T., Laevens, S. \& Vandamme, P. (2001). Burkholderia cepacia genomovar III is a common plant-associated bacterium. Appl Environ Microbiol 67, 982985.

Breazeale, S. D., Ribeiro, A. A. \& Raetz, C. R. (2002). Oxidative decarboxylation of UDP-glucuronic acid in extracts of polymyxinresistant Escherichia coli. Origin of lipid A species modified with 4amino-4-deoxy-L-arabinose. J Biol Chem 277, 2886-2896.

Brogden, K. A. (2005). Antimicrobial peptides: pore formers or metabolic inhibitors in bacteria? Nat Rev Microbiol 3, 238-250.

Burns, J. L., Wadsworth, C. D., Barry, J. J. \& Goodall, C. P. (1996). Nucleotide sequence analysis of a gene from Burkholderia
(Pseudomonas) cepacia encoding an outer membrane lipoprotein involved in multiple antibiotic resistance. Antimicrob Agents Chemother 40, 307-313.

Campbell, R. E., Mosimann, S. C., van De Rijn, I., Tanner, M. E. \& Strynadka, N. C. (2000). The first structure of UDP-glucose dehydrogenase reveals the catalytic residues necessary for the twofold oxidation. Biochemistry 39, 7012-7023.

De Leon, G. P., Elowe, N. H., Koteva, K. P., Valvano, M. A. \& Wright, G. D. (2006). An in vitro screen of bacterial lipopolysaccharide biosynthetic enzymes identifies an inhibitor of ADP-heptose biosynthesis. Chem Biol 13, 437-441.

Ernst, R. K., Yi, E. C., Guo, L., Lim, K. B., Burns, J. L., Hackett, M. \& Miller, S. I. (1999). Specific lipopolysaccharide found in cystic fibrosis airway Pseudomonas aeruginosa. Science 286, 1561-1565.

Figurski, D. H. \& Helinski, D. R. (1979). Replication of an origincontaining derivative of plasmid RK2 dependent on a plasmid function provided in trans. Proc Natl Acad Sci U S A 76, 1648-1652.

Flannagan, R. S., Aubert, D., Kooi, C., Sokol, P. A. \& Valvano, M. A. (2007). Burkholderia cenocepacia requires a periplasmic HtrA protease for growth under thermal and osmotic stress and for survival in vivo. Infect Immun 75, 1679-1689.

Flannagan, R. S., Linn, T. \& Valvano, M. A. (2008). A system for the construction of targeted unmarked gene deletions in the genus Burkholderia. Environ Microbiol 10, 1652-1660.

Ganz, T. (2003). Defensins: antimicrobial peptides of innate immunity. Nat Rev Immunol 3, 710-720.

Ge, X., Penney, L. C., van de Rijn, I. \& Tanner, M. E. (2004). Active site residues and mechanism of UDP-glucose dehydrogenase. Eur $J$ Biochem 271, 14-22.

Gold, R., Jin, E., Levison, H., Isles, A. \& Fleming, P. C. (1983). Ceftazidime alone and in combination in patients with cystic fibrosis: lack of efficacy in treatment of severe respiratory infections caused by Pseudomonas cepacia. J Antimicrob Chemother 12 (Suppl A), 331-336.

Helander, I. M., Kilpelainen, I. \& Vaara, M. (1994). Increased substitution of phosphate groups in lipopolysaccharides and lipid A of the polymyxin-resistant pmrA mutants of Salmonella typhimurium: a ${ }^{31}$ P-NMR study. Mol Microbiol 11, 481-487.

Hitchcock, P. J. \& Brown, T. M. (1983). Morphological heterogeneity among Salmonella lipopolysaccharide chemotypes in silver-stained polyacrylamide gels. J Bacteriol 154, 269-277.

Holden, M. T., Seth-Smith, H. M., Crossman, L. C., Sebaihia, M., Bentley, S. D., Cerdeño-Tárraga, A. M., Thomson, N. R., Bason, N., Quail, M. A. \& other authors (2009). The genome of Burkholderia cenocepacia J2315, an epidemic pathogen of cystic fibrosis patients. J Bacteriol 191, 261-277.

Hung, R. J., Chien, H. S., Lin, R. Z., Lin, C. T., Vatsyayan, J., Peng, H. L. \& Chang, H. Y. (2007). Comparative analysis of two UDP-glucose dehydrogenases in Pseudomonas aeruginosa PAO1. J Biol Chem 282, 17738-17748.

Isles, A., Maclusky, I., Corey, M., Gold, R., Prober, C., Fleming, P. \& Levison, H. (1984). Pseudomonas cepacia infection in cystic fibrosis: an emerging problem. J Pediatr 104, 206-210.

Iwanicka-Nowicka, R., Zielak, A., Cook, A. M., Thomas, M. S. \& Hryniewicz, M. M. (2007). Regulation of sulfur assimilation pathways in Burkholderia cenocepacia: identification of transcription factors CysB and SsuR and their role in control of target genes. J Bacteriol 189, 1675-1688.

Kox, L. F., Wösten, M. M. \& Groisman, E. A. (2000). A small protein that mediates the activation of a two-component system by another two-component system. EMBO J 19, 1861-1872. 
Loutet, S. A., Flannagan, R. S., Kooi, C., Sokol, P. A. \& Valvano, M. A. (2006). A complete lipopolysaccharide inner core oligosaccharide is required for resistance of Burkholderia cenocepacia to antimicrobial peptides and bacterial survival in vivo. J Bacteriol 188, 2073-2080.

Mahenthiralingam, E., Coenye, T., Chung, J. W., Speert, D. P., Govan, J. R., Taylor, P. \& Vandamme, P. (2000). Diagnostically and experimentally useful panel of strains from the Burkholderia cepacia complex. J Clin Microbiol 38, 910-913.

Mahenthiralingam, E., Urban, T. A. \& Goldberg, J. B. (2005). The multifarious, multireplicon Burkholderia cepacia complex. Nat Rev Microbiol 3, 144-156.

McPhee, J. B., Lewenza, S. \& Hancock, R. E. (2003). Cationic antimicrobial peptides activate a two-component regulatory system, PmrA-PmrB, that regulates resistance to polymyxin B and cationic antimicrobial peptides in Pseudomonas aeruginosa. Mol Microbiol 50, 205-217.

McPhee, J. B., Bains, M., Winsor, G., Lewenza, S., Kwasnicka, A., Brazas, M. D., Brinkman, F. S. L. \& Hancock, R. E. W. (2006). Contribution of the PhoP-PhoQ and PmrA-PmrB two-component regulatory systems to $\mathrm{Mg}^{2+}$-induced gene regulation in Pseudomonas aeruginosa. J Bacteriol 188, 3995-4006.

Miller, V. L. \& Mekalanos, J. J. (1988). A novel suicide vector and its use in construction of insertion mutations: osmoregulation of outer membrane proteins and virulence determinants in Vibrio cholerae requires toxR. J Bacteriol 170, 2575-2583.

Moreira, L. M., Videira, P. A., Sousa, S. A., Leitão, J. H., Cunha, M. V. \& Sá-Correia, I. (2003). Identification and physical organization of the gene cluster involved in the biosynthesis of Burkholderia cepacia complex exopolysaccharide. Biochem Biophys Res Commun 312, 323-333.

Mouslim, C. \& Groisman, E. A. (2003). Control of the Salmonella ugd gene by three two-component regulatory systems. Mol Microbiol 47, 335-344.

Nummila, K., Kilpelainen, I., Zähringer, U., Vaara, M. \& Helander, I. M. (1995). Lipopolysaccharides of polymyxin B-resistant mutants of Escherichia coli are extensively substituted by 2-aminoethyl pyrophosphate and contain aminoarabinose in lipid A. Mol Microbiol 16, 271-278.
Ortega, X. P., Cardona, S. T., Brown, A. R., Loutet, S. A., Flannagan, R. S., Campopiano, D. J., Govan, J. R. \& Valvano, M. A. (2007). A putative gene cluster for aminoarabinose biosynthesis is essential for Burkholderia cenocepacia viability. J Bacteriol 189, 3639-3644.

Patrzykat, A., Friedrich, C. L., Zhang, L., Mendoza, V. \& Hancock, R. E. (2002). Sublethal concentrations of pleurocidin-derived antimicrobial peptides inhibit macromolecular synthesis in Escherichia coli. Antimicrob Agents Chemother 46, 605-614.

Raetz, C. R. \& Whitfield, C. (2002). Lipopolysaccharide endotoxins. Annu Rev Biochem 71, 635-700.

Rossman, M. G. (1981). Evolution of glycolytic enzymes. Philos Trans $R$ Soc Lond B Biol Sci 293, 191-203.

Silipo, A., Molinaro, A., Cescutti, P., Bedini, E., Rizzo, R., Parrilli, M. \& Lanzetta, R. (2005). Complete structural characterization of the lipid A fraction of a clinical strain of $B$. cepacia genomovar I lipopolysaccharide. Glycobiology 15, 561-570.

Strominger, J. L., Maxwell, E. S., Axelrod, J. \& Kalckar, H. M. (1957). Enzymatic formation of uridine diphosphoglucuronic acid. J Biol Chem 224, 79-90.

Turner, J., Cho, Y., Dinh, N. N., Waring, A. J. \& Lehrer, R. I. (1998). Activities of LL-37, a cathelin-associated antimicrobial peptide of human neutrophils. Antimicrob Agents Chemother 42, 2206-2214.

Vaara, M., Vaara, T., Jensen, M., Helander, I., Nurminen, M., Rietschel, E. T. \& Mäkelä, P. H. (1981). Characterization of the lipopolysaccharide from the polymyxin-resistant pmrA mutants of Salmonella typhimurium. FEBS Lett 129, 145-149.

Wösten, M. M. S. M., Kox, L. F. F., Chamnongpol, S., Soncini, F. C. \& Groisman, E. A. (2000). A signal transduction system that responds to extracellular iron. Cell 103, 113-125.

Zanetti, M. (2004). Cathelicidins, multifunctional peptides of the innate immunity. J Leukoc Biol 75, 39-48.

Zhang, L., Parente, J., Harris, S. M., Woods, D. E., Hancock, R. E. \& Falla, T. J. (2005). Antimicrobial peptide therapeutics for cystic fibrosis. Antimicrob Agents Chemother 49, 2921-2927.

Edited by: J. H. Cove 